\title{
Undergraduate Research on Sustainability: Campus Energy Analysis and Building Energy Audits
}

\author{
Peter Jansson, James Blanck, Patrick Giordano, Dona Johnson, Sara Ross \\ Rowan University
}

\begin{abstract}
In an innovative junior-senior engineering clinic course ${ }^{1-2}$ four Rowan University undergraduate students worked on a multidisciplinary project to learn first hand what sustainability challenges are and what it means to be a professional energy auditor. Their task was to find out why Rowan University led a group of 20 peer universities and colleges in energy consumption per square foot and to assist the university in meeting its sustainability commitment to the Governor's Office and reduce its greenhouse gas emissions. This is not easy given the exponential growth this southern New Jersey University has been experiencing in student population, energy use and building square feet. With the assistance of their professor and a professional energy auditor the team learned the basics of building energy analysis, how to perform lighting surveys and energy audits and developed recommendations to the University's Energy Review Panel. Their recommendations could save the University thousands of energy dollars, over a million kilowatt hours and Btu's, and tons of greenhouse gas emissions when implemented. This team of electrical, civil/environmental and mechanical engineers completed two comprehensive energy audits and began sub-metering analysis to prioritize which buildings on campus should be investigated first based upon their energy consumption. As is true of many large campus facilities served by a single primary electric account not all buildings are sub-metered and just where all the power is being used on campus is unknown without detailed investigation and analysis. The team rapidly began to identify potential sources of data for their analysis and proposed inexpensive sub-metering for those locations where no equipment was available. The result of their work was the saving of significant money on external consultants and the ability of the Energy Review Panel to rapidly prioritize where it would focus its energy conservation efforts. They have become familiar with many industrial and commercial energy conservation techniques as part of this innovative laboratory experience. The results they have generated are creating motivation for a broader introduction of these concepts into the engineering curriculum.
\end{abstract}

Background

As our university's enrollment grows, new buildings are constructed and we increase our use of technology, we create a significant increase in our use of energy. In 2001 our university administration joined 46 other colleges and universities across New Jersey in endorsing a Sustainability Greenhouse Gas Action Plan for the state that calls for a 3.5\% reduction in greenhouse gas emissions below 1990 levels by $2005^{3}$. This commitment as well as ongoing priorities to keep student tuition costs low spawned an increasing need to conserve energy, and to cutback on energy costs across the Rowan University campus. A recent benchmark study that 
was completed for colleges and universities with similar campuses placed Rowan University in the $95^{\text {th }}$ percentile of energy usage. When compared to 20 colleges of comparable area and enrollment, our university ranked first in energy consumption per gross square foot of building space $^{4}$. The campus continues to grow, with plans to add at least two new buildings/dormitory complexes within the next two years. The annual electricity consumption for the university last year exceeded 32 million $\mathrm{kWh}$. The overall energy costs for the campus are over 4 million dollars annually. Additionally, estimates from the US Energy Information Agency's 1999 Commercial Buildings Energy Consumption Survey ${ }^{5}$ indicated that education buildings on average consume $8.7 \mathrm{kWh} /$ square foot of electricity annually and a U.S. EPA Energy $\operatorname{Star}{ }^{\circledR}$ Small Business Guide entitled Putting Energy Into Profits ${ }^{6}$ estimates that the total energy (heating, cooling and electricity) used by a college building is on average approximately 18.6 $\mathrm{kWh}$ /square foot annually. With Rowan using $16.9 \mathrm{kWh} / \mathrm{square}$ foot in electricity alone the prospects for savings appeared bright. The overall objective of this project was to develop a better understanding of where electrical energy was being used across the campus and to find cost-effective ways to help reduce electricity consumption and associated electric bills. "We are finding it more and more necessary to develop methods for cutting down on the energy consumed by our University. As we continue to expand our impact on the environment becomes more and more pronounced. Being part of an effort to save energy will leave a lasting experience that we can hold onto." -Pat, Jim, Sarah, Dona "The energy team"

Approach

The first step of the project was to determine which buildings were the largest consumers of electric power on campus. Prior to this work there was limited data to develop an accurate breakdown of campus-wide electric consumption. It was known that some sub-metering was present in a few buildings, although these few meters were not regularly read. Also, there was no consolidated analysis of the many individual Conectiv Power Delivery (local electric supplier) accounts that pertained to the University. The approach used to solve this problem was straightforward but rather tedious: significant time was spent gathering and analyzing sub-meter data, consolidating numerous accounts by building use type, etc. Each building was investigated in an attempt to locate an electric sub-meter, if one existed, and to determine its degree of functionality. Once this was completed, a database was formed to log each building for future reference. The location of the meter, if applicable, and whether it was functional was noted in each building's database. Once this was established, the next step was to regularly read each functional meter to get an energy profile for each building. This was done bi-weekly in the beginning, then weekly, then monthly, all recorded in a customized database. Gathering this information for each building was a crucial key in developing a good profile of where energy was flowing through the campus grid. Once a reasonable amount of data had been collected and validated we were able to take the data from our campus substation account from Conectiv and to compare it with all of the building data that had been gathered. The objective here was to see how much of the total energy consumption of the general account that the handful of submetered buildings made up. One un-metered building's energy use was estimated by way of demand readings taken at various times of the day, the buildings that were metered and regularly read as an element of this research investigation made up a substantial portion of the total electricity used on campus. It would have been quite valuable to have the remaining un-metered buildings outfitted with some form of sub metering, even if only temporarily, but this could not 
be accomplished within the timeframe and budget of the project. Once a data collection program was in place, the next step was for the team to learn how to become energy auditors and undertake an analysis of one small building (to learn on) to identify opportunities for energy efficiency improvements.

\section{Data Collection and Analysis}

The first portion of the project was devoted to developing the overall framework. Since this was the first semester that this project was in place, not all data needed to accomplish our goals was gathered and available to analyze; such as co-generation plant data, Conectiv Power Delivery data, location of meters, meter multipliers, etc. First, the team surveyed the entire campus; collecting basic information about each of the buildings, such as number of stories, construction type, age and use of building. After this, University Facilities personnel worked with the team to locate the mechanical rooms where the electric meters were located. Once each meter location was determined, the team designed a spreadsheet that would include all relevant information, as seen in Table 1.

Table 1: Building Data Collection Spreadsheet

\begin{tabular}{|c|c|c|c|c|c|}
\hline Building: & Rowan & Year: & 1998 & GSF: & 94,500 \\
\hline Key: & $13 \mathrm{~A}$ & $\begin{array}{r}\text { Construc } \\
\text { tion: }\end{array}$ & Concrete & $\begin{array}{r}\text { \# of } \\
\text { Meter }\end{array}$ & 1 \\
\hline $\mathrm{A} / \mathrm{C}$ & Yes & Meters & & & \\
\hline Use: & Classroom & $\begin{array}{l}\text { Location } \\
\text { of Meter: }\end{array}$ & $\begin{array}{l}\text { 4th floot, first } \\
\text { door on right } \\
\text { around comer }\end{array}$ & & \\
\hline Stories: & 4 & & & & \\
\hline Date & Time & $\mathrm{MWh}$ & Power Factor & Kvar & $\begin{array}{c}\text { Max } \\
\text { Demand }\end{array}$ \\
\hline $9 / 17 / 03$ & 12:30PM & 2352.49 & $-91 \%$ & -220 & $496 \mathrm{~kW}$ \\
\hline
\end{tabular}

"Each building on campus was given a separate spreadsheet, with information about that specific building, such as gross square footage (GSF), what key is used to open the mechanical room door, and directions to access the meter," said Dona, "Every time the meter was read, the date, time, and all pertinent electricity data was recorded." Some of the data that was important to us was power usage in kilowatt hours, power factor, and maximum demand in kilowatts. After analyzing the metering situation on campus, each building could be placed into one of four categories: no sub-metering, kilowatt-hours data only, metered but insufficient data, and full data (See Table 2). 
Table 2: Four Categories of Meters in University Buildings

\begin{tabular}{|c|c|c|c|}
\hline No Sub-Metering & kWh Data Only & $\begin{array}{c}\text { Metered, Insufficient } \\
\text { Data }\end{array}$ & Complete Data \\
\hline Bole Annex & Evergreen & Bozorth & Library \\
Bole Admin & Hawthorne & Esby Gym & Mimosa \\
Bosshart & Mullica & Westby & Memorial \\
Bunce & Robinson & Wilson & Rec Center \\
EPA & Winans & & Student Center \\
Laurel & Hollybush & & Rowan \\
Linden & & & Savitz \\
Chestnut & & & Science \\
Magnolia & & & \\
Oak & & & \\
Triad & & & \\
\hline
\end{tabular}

When analyzing meter readings over a month's time, an average daily kiloWatt-hour usage was found. From the average daily kilowatt-hour, the average kilowatt hour per gross square footage per day was calculated along with the average $\mathrm{kWh}$ per month, as seen in Table 3.

Table 3: Autumn 2003 Power Consumption for Metered Academic Buildings

\begin{tabular}{|l|c|c|c|}
\hline Building & kWh/day & $\mathbf{k W h} / \mathbf{d a y}$ *GSF) & $\mathbf{k W h} / \mathbf{m o n t h}$ \\
\hline Hawthorne & 3.3 & $2.24 \mathrm{E}-04$ & 100.4 \\
\hline Mullica & 8.2 & $2.52 \mathrm{E}-04$ & 246.4 \\
\hline Evergreen & 17.7 & $4.26 \mathrm{E}-04$ & 529.8 \\
\hline Book Store & 7.9 & $4.93 \mathrm{E}-04$ & 236.2 \\
\hline Holly Bush & 7.2 & $6.86 \mathrm{E}-04$ & 215.1 \\
\hline Team House & 239.9 & $2.79 \mathrm{E}-03$ & 7198.3 \\
\hline Mimosa & 627.3 & $9.76 \mathrm{E}-03$ & 18818.9 \\
\hline Rec Center & 2041.3 & $1.79 \mathrm{E}-02$ & 61240 \\
\hline Library & 5420.4 & $4.07 \mathrm{E}-02$ & 162612.8 \\
\hline Student Center & 5124.3 & $4.51 \mathrm{E}-02$ & 153727.7 \\
\hline Wilson & 5820 & $5.83 \mathrm{E}-02$ & 174600 \\
\hline Savitz & 3510.6 & $5.93 \mathrm{E}-02$ & 105319.1 \\
\hline Robinson & 5789.7 & $6.43 \mathrm{E}-02$ & 173691.4 \\
\hline Science & 10549.3 & $7.03 \mathrm{E}-02$ & 316477.5 \\
\hline Memorial & 3463 & $8.17 \mathrm{E}-02$ & 103889.4 \\
\hline Rowan & 11313.8 & $1.20 \mathrm{E}-01$ & 339414.9 \\
\hline
\end{tabular}


This data was graphed, as shown in Figure 1, and the top three consumers were found to be Rowan, Science and Wilson Halls. Using the sum of the estimates of monthly usage for the academic buildings, and comparing this total to the amount the whole campus used in the month of October, we found that our analysis accounted for $1.6(73 \%)$ of the 2.2 million $\mathrm{kWh}$ used.

Figure 1: Estimated Energy Usage in Kilowatt-hours in a 30-day month

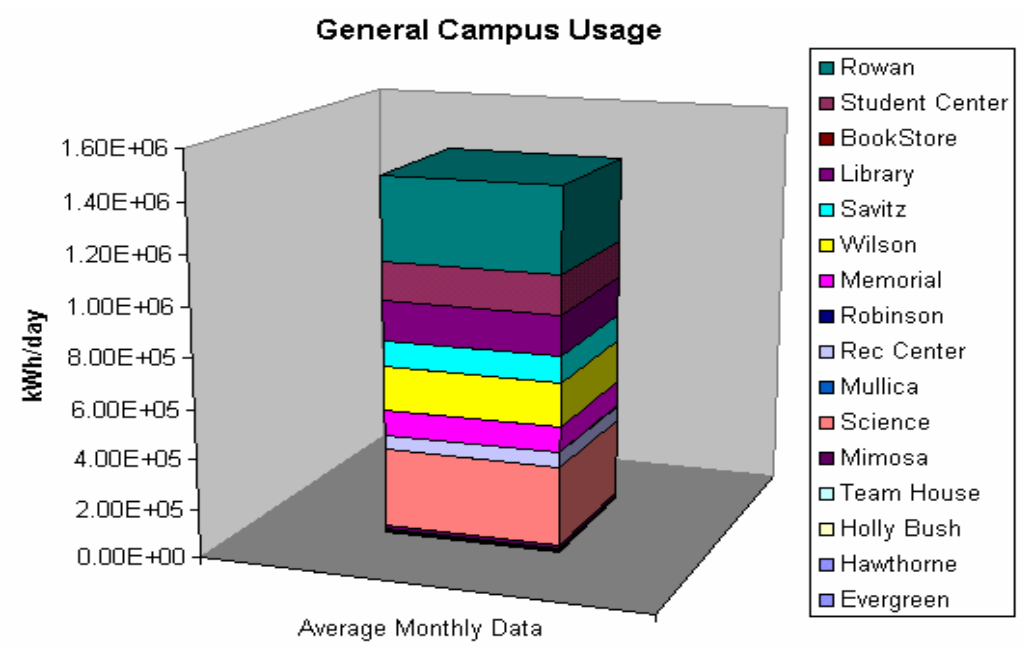

Having identified many of the buildings that were consuming significant electricity, the next step was to identify how much energy might be conserved within them, via the HVAC, lights, etc. In order to identify potential energy savings in a building a comprehensive energy audit needed to be preformed. An energy consultant who is trained in this area normally does this. One of the goals of this project was to develop energy analysis expertise on our campus and so an energy consultant was called in to help train the team on how to perform our own energy audits. The building selected for training purposes was the Team House on the north side of campus. The training at this point was essential, due to the fact that we would like to perform future audits on high usage buildings. Energy auditing is new field of research with respect to the many other areas of engineering that are taught in our curriculum. The demand for energy efficiency is growing rapidly at a time when technology growth and increasing fuel prices put pressures on corporate expenses. In addition, many companies are required to meet new clean air and efficiency standards and need to become more environmentally responsible. Energy efficiency will not only reduce energy costs but also the associated pollution. The team of students formed to help analyze the energy usage on Rowan University's Glassboro Campus, did not have a great deal of experience in the area of energy analysis. The team had to undergo training with the aid of their professor and a professional certified energy engineer, in order to understand the foundations of energy use. The student team's first energy audit was undertaken with the help of their professor and the energy professional. When the basics had been learned together, the student team went on to finish the audit on their own and present the results to their professor for review.

The Team House is an $8,607 \mathrm{ft}^{2}$ building, which houses Rowan University's football team and their faculty. The Team House was constructed in the 1970's and is most heavily used during the football season, and the training periods around it. In reviewing the Team House, it proved to be quite efficient in its current state. In interviewing faculty working in the building, we found them to be very energy conscious. During the summer months, air conditioners are only in operation if and when the room is occupied. Also, lights are turned off when rooms are 
not in use and at night all lights are generally turned off with the exception of outdoor lighting. The majority of the lighting fixtures found in the building were inefficient. Changing out the T12's to the more efficient T8 fixtures and the current T8's to newer models would produce an annual electricity savings of $\$ 2,098$. It is estimated that these fixtures can be replaced at a cost of $\$ 4,365$, producing a simple payback of only 2.1 years. Then by replacing all six of the exit signs that are now using two 15-watt bulbs with LED exit signs that use 10 watts, results in an annual savings of $\$ 95$ and an investment cost of only $\$ 300$ and a payback of 3.2 years. When converting the incandescent lights to fluorescent T8's, there would be an annual savings of $\$ 1,519$ with an investment cost of $\$ 170$ and a payback of only 0.1 years. The T8 fluorescent bulbs are the newest generation of lighting. Previously the most efficient method of lighting was the T12. The declaration of T8 and T12 reflects the overall size of the fluorescent tube. The T12 is a larger physical tube compared to the T8 tube; this decrease in size contributes to the overall energy efficiency of the lighting. The proposed lighting changes are cost effective, fairly simple to implement and provide a considerably short-term payback. In reviewing the water usage of the Team House, it was discovered that the current water consuming devices (faucets, shower heads, etc.) are quite efficient in their use of water. The faucets in the bathroom were spring loaded, which makes it impossible to leave water running and all of the showers have low-flow showerheads. Therefore no changes were recommended to any of the current water usage devices. In reviewing the mechanical room, we found that some things were not turned off when not in use. The boiler for the heater was left on all summer long and was working to maintain a $116^{\circ} \mathrm{F}$ temperature. It is not apparent why this operational practice is in place. At no cost this heater boiler could be turned off for the months of May through September and the savings to be provided as a result while not estimated to be very large may be of significant economic value. At the end of the audit it was recommended that the lighting be upgraded in the three areas described above and listed in the Table 4 below:

Table 4: Recommended Energy Efficient Measures

\begin{tabular}{|l|c|c|c|}
\hline Measure & Cost & Annual Savings & Simple Payback \\
\hline Convert T-12s to T-8s & $\$ 4,365$ & $\$ 2,098$ & 2.1 years \\
\hline Convert Incand. To T-8s & $\$ 170$ & $\$ 1,519$ & 0.1 years \\
\hline LED Exit Signs & $\$ 300$ & $\$ 95$ & 3.2 years \\
\hline All Improvements & $\mathbf{\$ 4 , 8 3 5}$ & $\mathbf{\$ 3 , 7 1 2}$ & $\mathbf{1 . 3}$ years \\
\hline
\end{tabular}

The total annual savings would be $\$ 4,835$, with a cost of $\$ 3,712$ and a total payback of 1.3 years. In addition, actions could be taken to ensure that boilers will be turned off during off seasons. These measures would help the Team House to become a more efficient and cost effective building.

Having successfully completed the small audit and receiving a favorable review from their professor, the team undertook a second audit. "We were very excited at this point," said junior electrical and computer engineer Pat Giordano. "We were ready for a new challenge." The new challenged placed before them was the audit on the University's largest consumer of electrical power; Rowan Hall. This building houses the College of Engineering on campus. This phase would include the students performing their own audit, with minimal guidance from the energy professional. Similar steps were taken for the Rowan Hall audit as with the Team House. 
Rowan Hall was built in 1997 and is 94,500 square feet. From the team's preliminary estimates Rowan Hall uses 4073 MWh of electricity per year (approximately 1/8th of the University total). The building structure extends four stories; the fourth floor is a mechanical penthouse. Three air handlers, one specifically dedicated to the auditorium, manage its ventilation. Rowan Hall is home to some of the most modern equipment on campus. The audit focused on three major areas, lighting, computers, and the HVAC system.

Upon completion of the lighting audit at Rowan Hall, it was observed that all of the lighting fixtures were highly efficient (T-8 lighting, etc.). Also, the exit signage was the LED type. External façade lighting was also efficient metal halide fixtures. The opportunities for savings here were associated with more optimal operational control. As engineering students the team was accustomed to the detailed usage habits of the building. On many days, it was observed that Atrium lighting remained lit on bright, sunny days providing minimal additional illumination to the ground. The team estimated that those lights operate close to $90 \%$ of each day. The light switches that control these lights have no automation or control to dim or shut them off during the day. Also, the light switches were behind a locked door with limited access for staff that may want to turn them off. Lighting operation in the hallways was also not optimal. The majority of lighting could be shut down during the daytime via photocontrol. Lighting in classrooms also poses a significant savings opportunity. In most cases at least $50 \%$ of the classrooms are left lit with no occupancy. Occupancy sensors could be installed to handle this problem. We also found that professors will leave their offices illuminated when they are at class or even during night. Colleagues have observed that the classroom lights are left on for aesthetical purposes throughout the night. We also found there is a great deal of external lighting on during daylight periods. On partially overcast days we see that the metal halide lights would come on and remain lit throughout the entire day. On inspection of the mechanical floor we saw that $90 \%$ of the fluorescent lighting on this floor remained on 24/7 with no occupancy. Throughout the course of the autumn semester we failed to see any attempt to shut off the unnecessary lighting on the fourth floor. Upon completion of the penthouse lighting audit we found that there are 46 fixtures that consume $2.9 \mathrm{~kW}$ at a total cost of $\$ 2321$ a year. That represents $25,789 \mathrm{kWh}$ /year. Occupancy sensors need to be equipped at various locations in the penthouse, with easily accessible override switches. Even during maintenance if the occupancy sensor were to shut the lights down, the necessary safety lights would still remain illuminated. With these modifications to the penthouse lighting we estimate that at a $90 \%$ reduction in run time to the lighting would produce $\$ 2,000$ dollars in saved electricity or $0.6 \%$ of Rowan Hall's use. Each classroom/lab consists of six LW83 and 12 MS42 fixtures. The LW83 fixtures account for $576 \mathrm{~W}$ and the MS42 fixtures account for $1920 \mathrm{~W}$. On a 24 -hour run cycle $5.9 \mathrm{kWh}$ of electricity is consumed. For the thirty classroom/labs in the College of Engineering the total price of electric for lighting exceeds $\$ 15.90$ a day. This does not account for the offices and labs that have similar lighting demand. Proper installation of occupancy sensors in classrooms is the most logical approach to this problem. The lights found in the hallways of the three floors consume 5.6kW. These lights are on 24 hours a day, seven days a week, and 365 days a year. At this rate Rowan Hall spends $\$ 4390$ per year in lighting hallways, which can often be shut down due to day lighting or lack of occupancy. It is clear that an occupancy sensor and photo-sensor placed in the hallways can cost-effectively regulate the amount of time that theses lights are on. One of the major costs associated with lighting in Rowan Hall is aesthetics. On the external façade of the building a large amount of lights are on at least 12 hours a day, in many cases some of the lights never shut off. Outside lighting accounts for $120 \mathrm{kWh}$ a day. This amounts to $\$ 3,942$ 
annually when we consider constant run cycle for 365 days. Table 5 shown below summarizes the lighting identified in major areas of the building; it is known that this analysis does not include individual professor's offices and departmental office space which will be estimated in a future project.

Table 5: Rowan Hall Lighting

\begin{tabular}{|r|r|r|r|r|r|}
\hline Location: & $\begin{array}{r}\mathbf{k W} \\
\text { Demand }\end{array}$ & $\begin{array}{r}\text { Daily } \\
\mathbf{k W h}\end{array}$ & $\begin{array}{r}\text { Annual } \\
\mathbf{k W h}\end{array}$ & $\begin{array}{r}\text { Annual } \\
\mathbf{C o s t}\end{array}$ & $\mathbf{\%}$ \\
\hline Class/Labs & n.a. & 177.0 & 64605 & $\$ 5,814$ & $54.6 \%$ \\
\hline Hallways & 5.6 & 134.4 & 49056 & $\$ 4,415$ & $41.5 \%$ \\
\hline 4th Floor & 2.9 & 69.6 & 25404 & $\$ 2,286$ & $21.5 \%$ \\
\hline Outdoor & 10.0 & 120.0 & 43800 & $\$ 3,942$ & $37.0 \%$ \\
\hline Total & $\mathbf{1 9}$ & $\mathbf{5 0 1 . 0}$ & $\mathbf{1 1 8 2 6 0}$ & $\mathbf{\$ 1 0 , 6 4 3}$ & $\mathbf{1 0 0 . 0 \%}$ \\
\hline
\end{tabular}

The Rowan Hall audit also estimated the effects that the computers have on electrical power consumption. Since the team was familiar with the habits of student computer use a good estimate of use could be made. The engineering building has a very extensive computer network. The computers are never shut down; but can go into a standby mode. This mode still draws significant electricity. The main computer first floor lab houses 46 computers. Each requires 30 minutes before the monitor powers down. When the computer is in active use it will draw 98.4 watts of electricity, when the computer is not in use that number drops to 93 watts. A key power drop occurs when the monitors hibernate and total usage drops to 41 watts. The following list shows estimates the usage levels of the first floor lab.

- $30 \%$ of computers in active state $3 \mathrm{hrs}$

- $50 \%$ of computers in active state $5 \mathrm{hrs}$

- $20 \%$ of computers in active state 6 hrs:

- $100 \%$ of computers have monitor off 10 hrs:

- First Floor Computer Lab Usage = 79.9 kWh/day

It was observed that most of the energy consumption by the computers was not during the use periods of school, but during the none-use times during the day and at night when the computers are in hibernation. It is also important to know that the labs are not opened during this period. After a certain time depending on the day the computer labs are locked up, but the computers are not shut down. It is a fact also that the computer lab is closed at least 1 day a week on Sunday. However the computers are still consuming significant electrical power as shown in Table 6. 
Table 6: First Floor Computer Lab Electrical Energy Use (kWh/day)

\begin{tabular}{|r|r|r|r|r|r|}
\hline & State: & Active & Inactive & Monitor Off & Totals \\
\hline \# of Units & 23 & & & & \\
\hline & Hours & 5 & 9 & 10 & \\
\hline & Energy & 11.3 & 19.3 & 9.4 & 40.0 \\
\hline \# of Units & 14 & & & & \\
\hline & Hours & 3 & 11 & 10 & \\
\hline & Energy & 4.1 & 14.3 & 5.7 & 24.2 \\
\hline \# of Units & 9 & & & & \\
\hline & Hours & 6 & 8 & 10 & \\
\hline & Energy & 5.3 & 6.7 & 3.7 & 15.7 \\
\hline All Units & & $\mathbf{2 0 . 8}$ & $\mathbf{4 0 . 3}$ & $\mathbf{1 8 . 9}$ & $\mathbf{7 9 . 9}$ \\
\hline & & $\mathbf{2 6 . 0 \%}$ & $\mathbf{5 0 . 4 \%}$ & $\mathbf{2 3 . 6 \%}$ & $\mathbf{1 0 0 . 0 \%}$ \\
\hline
\end{tabular}

Using the figures above we see that the first floor lab uses $74 \%$ of its energy while no one is using the computers. Our professor is working with our Information Technology Staff to develop a novel operation strategy that will keep these computers rapidly available for students but will put more of their components into 'sleep' mode (hard drives, etc.) when not in use Also the benefits of total shut down of the computers every night and during off days will be investigated during the Spring Term 2004. At present this one lab would appear to consume 29,165 kWh annually or about $0.7 \%$ of Rowan Hall's electricity. Together all the computer labs as well as staff, faculty and graduate student computer stations in the College of Engineering consume approximately $155,125 \mathrm{kWh}$ /year or $3.8 \%$ of Rowan Hall's power as shown in Table 7 . Senior electrical and computer engineering student Jim Blanck was quoted as saying, "The significance in energy wasted on inactive computers is amazing to me. To think that we could waste $155,125 \mathrm{kWh} /$ year is incredible. Though now that the problem has been addressed we can now take measures to regain the lost energy that is burnt up in inactive computers."

Of the 11MWh consumed by Rowan Hall daily, the machine labs and penthouse machinery are responsible for approximately $7 \mathrm{MWh}$. This is approximately $63 \%$ of the total energy used each day. Opportunities for improvement were uncovered during the energy audit. The HVAC system is a primary user of power in Rowan Hall. We have discovered that shortly after the building went into operation in 1997 one of the steam absorption chillers failed under warranty. The company provided a 300 ton electric chiller as a replacement. Once the warranty period ended the second absorption chiller failed, which has had negative effects on the College. Rather than fixing the broken steam absorption chillers, Rowan has decided to run the electric chiller continuously to meet the cooling demands of the structure. Significant electricity is required to operate the 300-ton chiller. Facility personnel informed our team that the chiller is operates from early April and through December. Due to the presence of cogeneration on the Rowan campus the steam absorption chillers were significantly more cost effective to run than the electric chiller, however, it required significantly more maintenance. In its original design steam was fed through the two steam absorption chillers, one sized for the summer load and the other for the winter load. Since the system was initially set up for steam absorption the condensation return pumps are now oversized for the low-pressure return with the building 
operating on the electric chiller. Our team believes that the significant savings will be obtained by downsizing the return pumps, if Rowan Facility personnel choose to keep the building on the electric chiller.

Table 7: Rowan Hall Total Computer Electrical Energy Use (kWh/day)

\begin{tabular}{|r|r|r|r|r|r|}
\hline Location: & State: & Active & Inactive & Monitor Off & Totals \\
\hline Labs: & \# units & & & & \\
\hline 1st Floor & 46 & 20.8 & 40.3 & 18.9 & 79.9 \\
\hline Unix & 22 & 17.5 & 30.2 & 20.2 & 67.9 \\
\hline 204 & 10 & 4.2 & 7.6 & 5.1 & 16.9 \\
\hline 238 & 8 & 6.0 & 10.1 & 4.8 & 20.9 \\
\hline 3rd Floor & 22 & 12.5 & 22.0 & 11.4 & 46.0 \\
\hline Lab Total & $\mathbf{1 0 8}$ & $\mathbf{6 0 . 9}$ & $\mathbf{1 1 0 . 2}$ & $\mathbf{6 0 . 4}$ & $\mathbf{2 3 1 . 6}$ \\
\hline Individual & \# units & & & & \\
\hline 1st Floor & 38 & 16.1 & 29.1 & 15.9 & 61.1 \\
\hline 2nd Floor & 43 & 18.2 & 32.9 & 18.0 & 69.2 \\
\hline 3rd Floor & 39 & 16.5 & 29.9 & 16.4 & 62.7 \\
\hline Sub Total & $\mathbf{1 2 0}$ & $\mathbf{5 0 . 8}$ & $\mathbf{9 1 . 9}$ & $\mathbf{5 0 . 4}$ & $\mathbf{1 9 3 . 0}$ \\
\hline All & $\mathbf{2 2 8}$ & $\mathbf{1 1 2}$ & $\mathbf{2 0 2}$ & $\mathbf{1 1 1}$ & $\mathbf{4 2 5}$ \\
\hline & & & & & \\
\hline
\end{tabular}

Rowan Hall HVAC includes three air handling units (AHU's). The first two operate to condition the classrooms, labs, and office inside the building. The third is dedicated to the auditorium. As engineering students who spend much time in the Rowan Auditorium we have experienced first hand some problems with AHU \#3. On many occasions while in class we witnessed the temperature inside the auditorium as abnormally cold and very humid. Upon visual inspection of the unit we saw that this air handler was in poor condition. We were unable to find the variable speed control for AHU \#3; however we were able to locate controls for the other two. Both AHU \#1 \& \#2 have variable speed pumps. On the multiple occasions that we visited the penthouse we have failed to see the pumps running any less than 59Hertz. This system appears to have never been properly set up. Without this system being properly utilized the pumps will remain at maximum speed $100 \%$ of the time, even when the building does not require the full head pressure. Here are some of the figures that we found with respect to the HVAC system. The Carrier centrifugal electric chiller runs at 460 volts consuming 12 amps. Using the data specified for the run-time and duty cycle of this system we see that it uses $3.6 \mathrm{MWh}$ each day. This accounts for $36 \%$ of the daily load during its operation. This is one reason why the steam absorption chiller is much more economical. The only draw back is the heavy-duty pumps needed to send the steam back via the lower pressure line back to the boiler. The high maintenance required for the steam absorption chiller is the main reason that the electric system is still in place. The fourth floor penthouse is not the only floor with machinery. Rowan Hall plays host to a series of high power machinery. In the first floor mechanical lab many machines run almost constantly throughout the workday. These machines are shut down during weekends and nights. One of the biggest machinery we have is a CNC machine. This is a computer controlled milling machine. From our analysis this machine has two inputs both running at 220 volts. However the data that we could access for the machine states that each line 
draws approximately 90-100 amps while under load. We estimate that this machine will run about close to 10 hours a day 5 days a week. At those estimations we see that this machine consumes $436 \mathrm{kWh}$ per day. There are other machines that run for that same amount of time as the CNC. They draw on the computer controlled lathes and other various shop machinery range from $20-52$ amps a piece at 220 volts. Our estimate for the first floor is that machine shops consume approximately 1-1.5 MWh's daily. On the second and third floors there are also labs that contain machinery. This accounts for about $2 \mathrm{MWh}$ per day shared between the remaining floors. The second floor hosts various lab rooms. One is designated for civil and chemical engineers and the remainder labs host electrical engineers. In the electrical labs we see many different types of machinery ranging from oscilloscopes and power supplies to magnetic flux leakage metering equipment. This equipment is not as energy intensive as the mechanical labs on the first floor. The second floor has been estimated to consume around $1 \mathrm{MWh}$ a day.

The remaining $1 \mathrm{MWh}$ has yet to be fully accounted for, but some of it is believed to be consumed on the third floor, in labs primarily dedicated to civil and chemical engineering experimentation. An analysis of this floor discovered 30 high temperature heaters for lab experiments running. Signage indicated that the machines were operational and that they were not to be shut off due to experimental processes. Running an analysis on each machine we found that they together consume $540 \mathrm{kWh}$ a day, assuming that they are ran non-stop during their testing procedure. The other $460 \mathrm{kWh}$ are presently unassigned but some part is associated with the electric cement mixers and various other machines used by the civil engineers.

Figure 2 represents the Team's first estimate of the overall breakdown of electric power usage in Rowan Hall, it is a significant step forward in understanding power flow and energy utilization within the building.

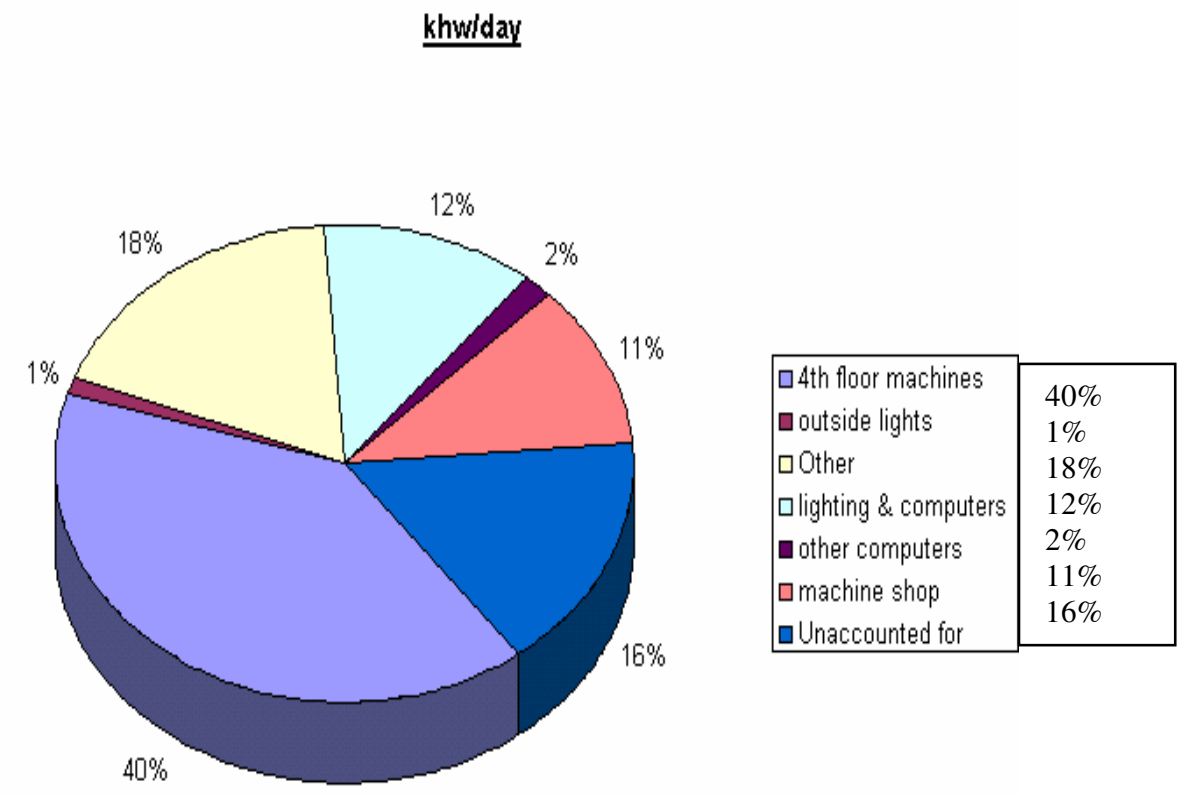

Another key contribution of this project was creation of a database for all of the electric meters on campus. Prior to September of 2003, little data was available for any of the buildings on campus. After investigating Rowan Hall for the better part of 4 months, it was observed that the electricity consumed averages $11,314 \mathrm{kWh}$ a day during the autumn semester. This ranks the 
building as the highest energy user on campus. Another key observation was that the demand at Rowan Hall does not fall off significantly from the peak afternoon load. During the peak time of the semester readings of Rowan Hall meters were conducted regularly to identify the load demands during the night. At 9p.m.on October 13, 2003, the demand on the building was 593 $\mathrm{kW}$; during the earlier part of that day (at $2 \mathrm{p} . \mathrm{m}$.) the demand was $626 \mathrm{~kW}$. While initially we thought this to be very high when very few people were in the building, we observed all classroom lights on, machines being used for experiments, and the electric chiller running near full load. It is the team's belief that improved control of the lighting and ventilation of Rowan Hall will yield significant savings.

Our analysis of the economics of lighting controls indicates that motion sensors can have a very short payback, see Figure 3, which can be equipped in classrooms.

Figure 3: Wall mounted motion sensor

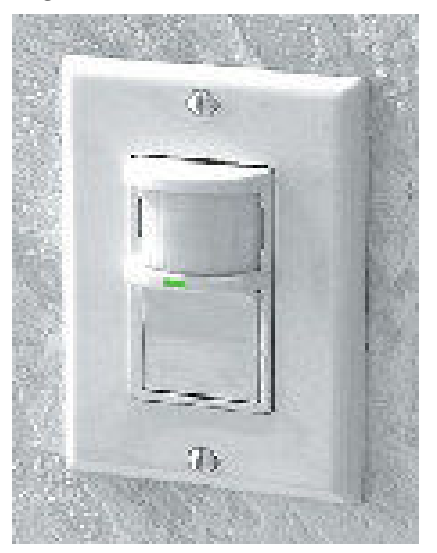

The picture to the left is a motion sensor that doubles as a switch. This is particularly good since it can be installed with relative ease, utilizing existing wiring. The retail price is $\$ 24$. 30 classroom/labs could be outfitted for under $\$ 1500$. This cost is a small compared with the money that can be saved. These controls will provide an estimated $35 \%$ savings of the $\$ 6,700$ spent lighting these areas each year. This assumes no occupancy in the classrooms from 10p.m. to 8a.m. every night. For the hallways, the infrared meter most appropriate to the task would be the Leviton infrared (long range) sensor. This device can control a corridor of up to 120 feet and costs slightly under $\$ 100$ installed. 12 are required to effectively cover the 6 main hallways in the building. The payback on this investment is about 1.2 years.

The mechanical systems are where the most savings can be achieved. The 300-ton electric chiller consumes 3.6MWh a day, whereas if the steam abortion chillers were fixed the load could be reduced by an estimated $70 \%$. Also AHU \#3 needs to receive maintenance to correct its erratic operational behavior. Discussions with Facility personnel indicate that AHU $\# 1$ and AHU \#2 were designed to be redundant and back up each other. In operation this is clearly not the case, they both operate simultaneously; practically doubling the energy consumed when one AHU could perform in the place of the two. It was also observed that the variable speed pumps are not actually functioning per design, since there is no indication that the speed of these pumps is ever varied. The team's observations were that these pumps run at near 100\% all the time. While we are unable to put an exact price tag on fixing the HVAC systems without further detailed investigation and receipt of proposals from subcontractors, estimates from professionals in the HVAC field approximate savings of $890,000 \mathrm{kWh}(\$ 80,000)$ a year. The actual route chosen in resolution of the identified areas for improvement will heavily influence the actual savings that can be achieved. Pat was asked about his take on the Rowan Hall audit and responded as follows, "I cannot believe the amount of energy that is wasted every day in the mechanical and lighting system in Rowan Hall. By completing this audit we can now make the proper steps towards fixing the major problems, and begin to save the university money and reduce the universities overall greenhouse gas production."

One last audit area identified two (2) pond aerator pumps found in the manmade pond behind Rowan Hall. Together they consume $176 \mathrm{kWh} /$ day. This is a great deal of energy when one considers that these pumps have run continuously since the building was first opened in 1997. Further, because of continuous operation they are changed annually due to pump failure. 
The total electric used is $64,333 \mathrm{kWh} /$ year. Discussions with facilities indicate that the pumps could be cycled off at night (during non-freezing weather) and save approximately 19,300 kWh.

If all of the improvements we have proposed (see Table 8) were to be implemented Rowan Hall could save over $\$ 90,000$ annually with a decrease in its consumption of electricity by nearly $2800 \mathrm{kWh} /$ day (25\%). It would then be the \#2 energy consuming building on campus.

Table 8: Rowan Hall Electrical Energy Savings

\begin{tabular}{|r|r|r|r|r|r|}
\hline & $\mathbf{k W}$ & Usage & Savings & Annual & \\
\hline Area: & Demand & $\mathbf{k W h}$ & $\mathbf{k W h}$ & Savings & $\mathbf{\%}$ \\
\hline Lighting & $>19$ & 118260 & 48673 & $\$ 4,381$ & $41.2 \%$ \\
\hline Computers & 28.5 & 155125 & 57305 & $\$ 5,157$ & $36.9 \%$ \\
\hline HVAC Equipment & $>500$ & 1651844 & 888888 & $\$ 80,000$ & $53.8 \%$ \\
\hline Outdoor Pumps & 7.3 & 64333 & 19300 & $\$ 1,737$ & $30.0 \%$ \\
\hline Total & $\mathbf{5 5 4 . 8}$ & $\mathbf{1 9 8 9 5 6 2}$ & $\mathbf{1 0 1 4 1 6 6}$ & $\mathbf{\$ 9 1 , 2 7 5}$ & $\mathbf{5 1 . 0 \%}$ \\
\hline
\end{tabular}

At various times during the semester, the team met with the University's Energy Review Panel (ERP) on campus to help facilitate data collection and to keep them abreast of the study's progress. The team made its final recommendations at the close of term in December 2003. The recommendations included

1) Installation of better meters in the buildings needing them,

2) Adding metering to the buildings without any metering,

3) Implementation of the recommendations of the team's two (2) energy audits (Rowan Hall and the Team Building),

4) A continued student meter reading program for all current meters to further update the energy usage profile of the buildings, and

5) Expansion of student energy audits to the remaining campus buildings.

There are plans to continue to meet regularly with the Energy Review Panel to get more input about energy usage on campus and how student engineering teams can best assist the Facilities Department in reaching and meeting our greenhouse gas reduction commitment. The results of the work completed to-date have been quite encouraging with the identification of nearly $25 \%$ energy savings in one of the campuses largest buildings. Continuation of this project each semester is planned to not only save the University money, but to save energy, the environment and to add an important new dimension to the education of our engineers. 


\section{Bibliography}

1 J. L Schmalzel, A. J. Marchese, J. Mariappan and S. A. Mandayam, "The Engineering Clinic: A four-year design sequence," presented at the 2nd An. Conf. of Nat. Collegiate Inventors and Innovators Alliance, Washington, D.C., 1998.

2 J. L Schmalzel, A. J. Marchese and R. P. Hesketh, "What's brewing in the Clinic?," HP Engineering Educator,2:1, Winter 1998, pp. 6-7.

${ }^{3}$ New -Jersey Department of Environmental Protection - Division of Science, Research and Technology: New Jersey Sustainability Greenhouse Gas Action Plan, Program/Partners http://www.state.nj.us/dep/dsr/gcc/gcc.htm

${ }^{4}$ ARAMARK Facility Services, Confidential Audit of Rowan University Facilities, Spring 2001

${ }^{5}$ Energy Information Agency - Information on the Commercial Buildings Sector: Detailed Tables: http://www.eia.doe.gov/emeu/cbecs/

${ }^{6}$ United States Environmental Protection Agency, Putting Energy Into Profits, Energy Star ${ }^{\circledR}$ Small Business Guide, Publication 430-B-97-040 December 1997 (updated Spring 2000)

\section{Biographies}

PETER MARK JANSSON is an Associate Professor of Electrical and Computer Engineering at Rowan University and leads numerous Junior Senior Engineering Clinic Teams in solving real world engineering problems each semester. He teaches Networks, Sustainable Design, Power Systems and research includes renewable power systems. He received a PhD from the University of Cambridge, MSE from Rowan University and BSCE from MIT.

JAMES BLANCK is a senior electrical and computer engineering student at Rowan University

PATRICK A GIORDANO, JR. is a junior electrical and computer engineering student at Rowan University who enjoys the practice of "hands-on" engineering and excels at it. His plans include achieving his masters at Rowan after graduating with his BSECE with minors in math, physics and computer science.

DONA JOHNSON is a junior mechanical engineering student at Rowan University and a member Society Of Women Engineers (SWE), the SGA rep for American Society of Mechanical Engineers (ASME), and a member of the Golden Key International Honor Society.

SARA ROSS is a senior civil and environmental engineering student at Rowan University and will receive her BSCE in the spring of 2004. She is a member of the American Society of Civil Engineers, Society of Women Engineers and the Association of State Dam Safety Officials. 